Gut, 1982, 23, 847--853

\title{
Simultaneous culture of saliva and jejunal aspirate in the investigation of small bowel bacterial overgrowth
}

\author{
I HAMILTON, * B W WORSLEY, I COBDEN, E M COOKE, J G SHOESMITH, \\ and $A$ T R AXON
}

From the Gastroenterology Unit, The General Infirmary, Leeds

SUMmARY Both saliva and jejunal aspirate were cultured from 22 patients with suspected small bowel bacterial overgrowth and from eight controls. Large numbers of organisms $\left(>10^{6} / \mathrm{ml}\right)$ were recovered from the jejunal aspirate of 16 subjects, in five of whom the same organisms were present in similar relative proportions in the saliva, suggesting contamination of the sample with saliva, while in 11 the jejunal organisms differed from those in saliva. In eight of these the jejunal flora was a typical 'faecal' flora usually associated with small bowel bacterial overgrowth but, in three, the jejunal floral was superficially similar to that of saliva. Distinct subpopulations of bacteria, typically Gram-positive non-sporing rods, were, however, evident in the jejunum of these patients, and were also recovered, in smaller numbers, from the jejunum of controls, suggesting that they form a distinct jejunal microflora. Culture of saliva in addition to jejunal aspirate may be useful in the recognition of contamination of the proximal small bowel with saliva, and in the diagnosis of small bowel bacterial overgrowth.

The diagnosis of small bowel bacterial overgrowth may be difficult, and, although several techniques based on the metabolic properties of bacteria have been developed to aid in diagnosis, none has sufficient accuracy and reliability to replace bacteriological culture of a sample of fluid aspirated from the jejunum. ${ }^{1}$ The interpretation of the results of culture, however, is not straightforward, and the relevance of 'salivary' organisms isolated from the jejunum is uncertain, bacteria such as streptococci, lactobacilli and other Gram-positive non-sporing rod-shaped organisms (G+NSR) having been isolated from the normal small bowel, particularly after eating. ${ }^{2}$ This demonstration of a transient jejunal flora of 'salivary' organisms has prompted a belief that the isolation of such bacteria does not imply true colonisation of the small bowel, and they may be disregarded as a cause of symptoms. It is probable, however, that the majority of organisms entering the small bowel come from the mouth, and it might be expected that, in a proportion of patients in whom the small bowel is prone to colonisation due to abnormal morphology or motility, true

\footnotetext{
* Address for correspondence: Dr I Hamilton. Gastroenterlogy Unit. The General Infirmary, Leeds LS1 3EX.

Received for publication 29 January 1982
}

colonisation with 'salivary' organisms may occur. The environmental differences between the mouth and small bowel are considerable and organisms more tolerant of $\mathrm{pH}$ changes or the presence of bile would be more capable of surviving in the jejunum. Thus 'salivary' organisms isolated from the small bowel might demonstrate qualitative and quantitative differences from those in saliva if true small bowel colonisation has occurred, but not if their presence is due merely to transient contamination.

The isolation of 'faecal' organisms - for example, coliforms, bacteroides and other anaerobes normally present in the colon - in excess of an arbitary number from the small bowel, is conversely considered sufficient evidence to diagnose small bowel bacterial overgrowth. ${ }^{3}$ The results of culture of jejunal aspirate, however, are usually interpreted without knowledge of the bacteria present in the patient's saliva at the time of sampling, and it seems likely that both false-positive and false-negative diagnoses are made because of this.

We have compared the microbial flora of saliva and jejunum in patients in whom small bowel bacterial overgrowth was suspected, and in controls, to determine whether a subpopulation of patients with small bowel overgrowth of 'salivary' organisms may be defined, and to determine also the extent to 
which contamination of the jejunum with saliva may cause the results of culture of jejunal aspirate alone to be misleading.

\section{Methods}

PATIENTS

Samples of saliva and jejunal fluid were taken from 30 patients. In 22 small bowel bacterial overgrowth was considered a possible cause of diarrhoea or malabsorption. The remaining eight patients were studied as controls at the time of duodenal intubation for a Lundh test, to exclude pancreatic disease as a cause of abdominal pain.

Saliva was collected into a sterile universal container, the mouth rinsed, and a sterile duodenal sump tube passed into the proximal jejunum under fluroscopic control. The first $5 \mathrm{ml}$ fluid aspirated was discarded, and a sample was aspirated through a syringe, and injected into sterile anaerobic collection bottles, rendered oxygen-free in an anaerobic cabinet and containing 'deoxo' catalyst. Samples were processed immediately or diluted in pre-reduced anaerobically sterilised (PRAS) glycerol broth and frozen under liquid nitrogen.

All anaerobic manipulations were performed in an anaerobic glove box (Forma Scientific, Raven Scientific, England) in an atmosphere of $10 \% \mathrm{CO}_{2}$ $10 \% \mathrm{H}_{2} 80 \% \mathrm{~N} 2$. Quantitative bacterial counts were performed by plating serial dilutions of samples in PRAS-tryptone $(1 \%)$ gelatin $(0.1 \%)$ on to the media, shown in Table 1. All anaerobic media was freshly prepared and stored in the glove box for at least two days before use.

Aerobic cultures were also prepared as shown in Table 1. All plates were incubated at $35^{\circ} \mathrm{C}$ for the periods shown (Table 1). After incubation each colony type on the various media was enumerated and a representative characterised. Strict anaerobes could generally be recognised by their sensitivity to metronidazole ( $5 \mu \mathrm{g}$ disc). G+NSR could be subdivided into strict anaerobes, facultatively anaerobic types, or types of intermediate aerotolerance, on the basis of their growth in air and $5 \% \mathrm{CO}_{2}$ on chocolate agar.

Other distinguishing tests included: colony morphology, Gram stain, catalase activity, indole production, nitrate reduction, gelatin hydrolysis, aesculin hydrolysis, tolerance of bile and ethyl violet, sugar fermentations, and anti-biograms. On occasion, analysis of volatile end-products of metabolism by gas-liquid chromatography was used.

\section{Results}

CONTROLS SUBJECTS

Jejunal aspirate in four controls (pts 1-4) was sterile or yielded very small numbers of organisms. In one
Table 1 Details of media used and organisms isolated

\begin{tabular}{|c|c|c|}
\hline Media & $\begin{array}{l}\text { Incubation period } \\
\text { (days) }\end{array}$ & Organisms isolated \\
\hline \multicolumn{3}{|l|}{ Anaerobic } \\
\hline Blood agar (ba) & 7 & Total anaerobes \\
\hline Kanamycin/vancomycin & & \\
\hline $\begin{array}{l}\text {-ba } \\
\text { Ethyl violet/neomycin }\end{array}$ & $5-7$ & Bacteroides \\
\hline $\begin{array}{l}\text { - ba } \\
\text { Veillonella agar/ }\end{array}$ & $5-7$ & Fusobacteria \\
\hline Vancomycin & 5 & Veillonella \\
\hline $\begin{array}{l}\text { Tomato juice agar/ } \\
\text { sorbic acid }\end{array}$ & $5-7$ & $G+N S R$ \\
\hline Egg yolk/neomycin agar & $2-3$ & Clostridia \\
\hline \multicolumn{3}{|l|}{ Aerobic } \\
\hline Chocolate agar $+5 \% \mathrm{CO}_{2}$ & Up to 5 & $\begin{array}{l}\text { Total aeorobes and } \\
\mathrm{CO}_{2} \text { dependent } \\
\text { types }\end{array}$ \\
\hline Maconkey agar & $1-2$ & Coliforms \\
\hline Mitis salivarius agar & $1-2$ & Strep. salivarius \\
\hline Thallous acetate & $\begin{array}{l}1 \text { day } 37^{\circ} \mathrm{C} \\
3 \text { days } 22^{\circ} \mathrm{C}\end{array}$ & Strep. faecalis \\
\hline Sabouraud's agar & $1-4$ & Yeasts \\
\hline $5 \%$ salt agar & $1-2$ & Staphylococci \\
\hline
\end{tabular}

(pt 6) there was a significant number $\left(>2 \times 10^{5} / \mathrm{ml}\right)$ of organisms cultured which were identical with the organisms cultured from saliva, both in type and in their relative proportions (Table 2 ). In the remaining three controls (nos. 5, 7, and 8) smaller numbers $\left(<10^{4} / \mathrm{ml}\right)$ of organisms were cultured (Table 2). These were predominantly G+NSR morphologically distinguishable from superficially similar organisms recovered from the saliva of the same patient.

\section{PATIENTS WITH SUSPECTED SMALL BOWEL}

\section{BACTERIAL OVERGROWTH}

Total viable bacterial counts in jejunal aspirate of 16 patients was of the order of magnitude associated with small bowel bacterial overgrowth $\left(>10^{6}\right.$ organisms $/ \mathrm{ml}$ ). In five cases the organisms recovered from the jejunum were qualitatively identical with those in the autologous saliva, and were present in similar relative proportions suggesting that their presence in the jejunal aspirate might be the result of salivary contamination (Table 3 ); in one of these (no. 26) large numbers of coliforms as well as more typical oral organisms were isolated from both saliva and jejunal aspirate.

The bacteria cultured from the jejunal aspirate of the remaining 11 patients in this group (nos. 9-19) differed from those in the saliva (Table 4). In eight, (nos. 9-15, 17) the small bowel bacteriology was typical of the flora frequently termed 'faecal' or 'colonic', with appreciable numbers of coliforms 
Saliva and jejunal aspirate in small bowel bacterial overgrowth

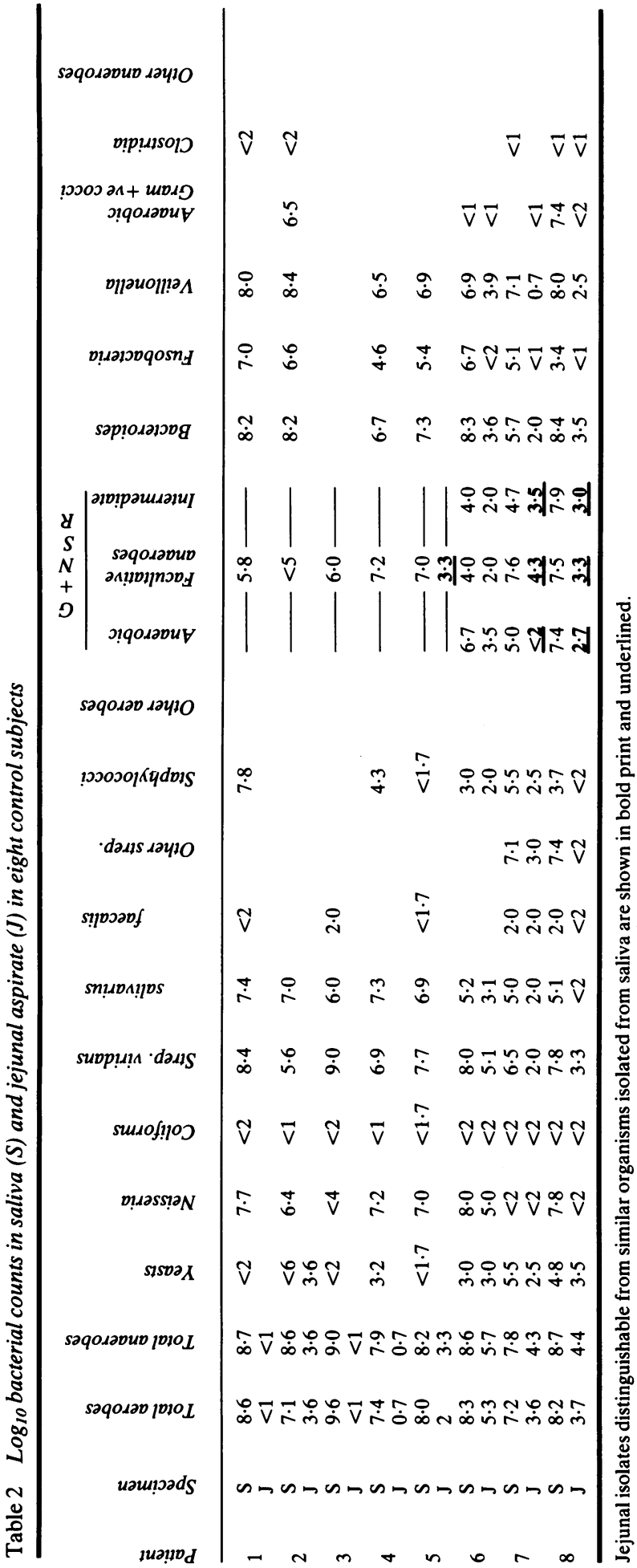

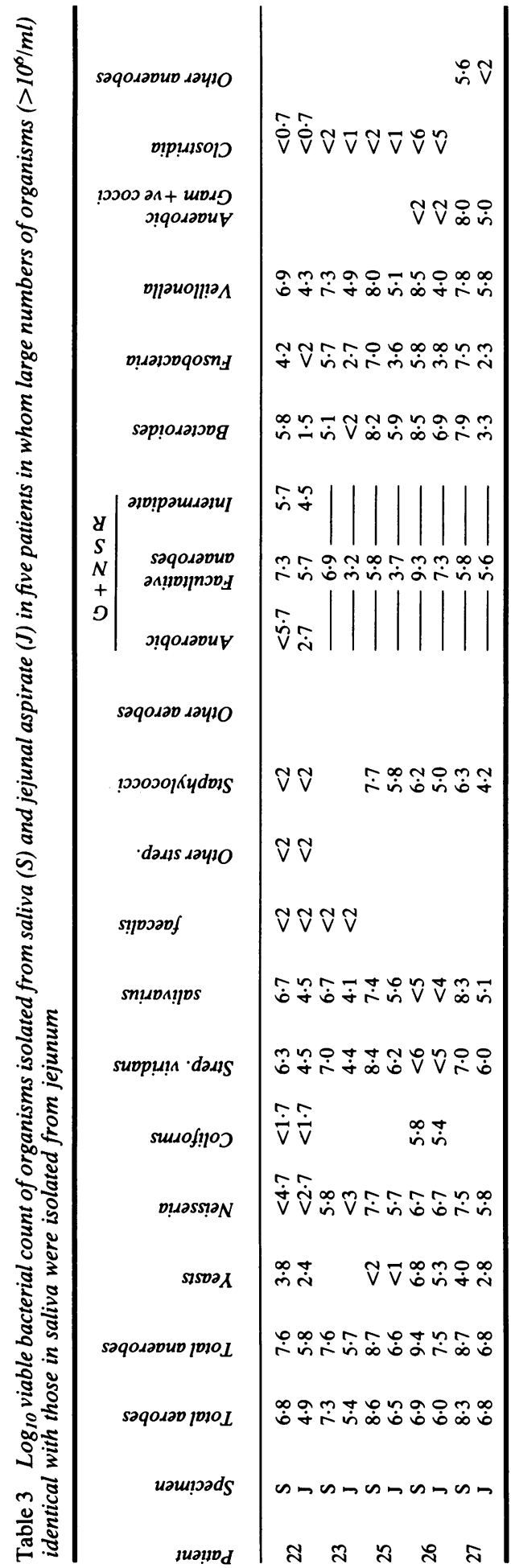


present, often in association with faecal streptococci and clostridia. In only one of these eight patients, however, was the jejunal flora truly similar to that normally found in the large bowel with a preponderance of faecal-type anaerobic Gramnegative rods - for example, Bacteroides fragilis while in the remaining seven the jejunal organisms, particularly Bacteroides and Fusobacteria, had both faecal and salivary components, with some strains isolated which were identical with those in matched saliva samples - for example, $B$. oralis, $B$. melaninogenicus, and $F$. nucleatum. In three patients (nos. $16,18,19)$, the jejunal flora was superficially similar to that of saliva and yet distinct populations, particularly of G+NSR, could be recognised on more detailed examination. Jejunal G+NSR could be distinguished from those in the same patients' saliva on the basis of colonical morphology, Gram strain morphology aerotolerance and biochemistry (Table 5) and were often present in different relative proportions at the two sites. Distinct jejunal strains of G+NSR were also present in three of the eight patients with the typical 'faecal' flora described earlier (patients 11, 14, 17).

Very much lower numbers of bacteria $\left(<10^{5} / \mathrm{ml}\right)$ were isolated from the small bowel of the remaining six patients (Table 6). Jejunal aspirate of one (no. 20) was sterile and in one (no. 24) organisms recovered were identical with those present in the saliva, and were present in the same relative proportions at the two sites, again suggesting contamination of the proximal small bowel with saliva. In three patients (nos. 28-30) the organisms recovered from jejunal aspirate were again superficially similar to those in saliva, and yet distinct salivary populations of $G+$ NSR could be recognised on detailed examination. In the final patient (no. 21) only small numbers of yeasts were isolated from the jejunum.

\section{Discussion}

The possible inaccuracies inherent in interpreting the bacteriology of jejunal aspirate without detailed knowledge of the microbial flora of the patient's saliva at the time of sampling is suggested by these results. On several occasions jejunal aspirate, both from controls and from patients investigated to exclude small bowel bacterial overgrowth, yielded appreciable numbers of organisms which were clearly derived from saliva. While in the majority of cases these organisms were typically 'salivary' in nature, on one occasion coliforms were also isolated from both jejunum and mouth of a debilitated patient with poor oral hygiene. Contamination of the jejunum with saliva is a more likely explanation than the coincident development of a similar grossly abnormal flora at two sites. In another four patients organisms identical with those in saliva were isolated from the jejunum in sufficient numbers to raise the possibility of small bowel overgrowth, but the diagnosis must be questioned when it can be demonstrated that the jejunal flora might be derived solely from dilution of saliva. In each of these cases an alternative diagnosis has subsequently been reached and appropriate treatment has relieved their symptoms, and in none were glucose-hydrogen or ${ }^{14} \mathrm{C}$-glycocholate breath tests ${ }^{4}$ positive.

In contrast no other diagnosis could be made in the remaining 11 patients from whom $>10^{6}$ organisms $/ \mathrm{ml}$ of jejunal aspirate were isolated, and in each of these cases the jejunal bacteria differed from those in saliva. Glucose-hydrogen breath test was positive in eight and negative in three; ${ }^{14} \mathrm{C}$-glycocholate breath test was positive in three and negative in three, and all 11 had a satisfactory clinical response to antibiotic treatment. We believe that these patients' symptoms were due to small bowel bacterial overgrowth, although in three the predominant organisms isolated from the jejunum were 'salivary' in nature. It is only by detailed morphological and biochemical examination that the differences between these organisms and those predominant in saliva could be recognised. The ability to survive in a bile-rich environment is one mechanism by which strains of G+NSR may be selected to colonise the small bowel, as in the example shown in Table 5, and the presence of such strains of bacteria in the jejunum in higher numbers than in saliva is strong evidence that true colonisation of the small bowel has occurred, as opposed to the loss of bile-sensitive strains during passage through the small bowel.

Similar strains of G+NSR distinguishable from those in saliva were present in lower numbers in the jejunal aspirate of controls, and also of three patients in whom small bowel overgrowth was suspected but not definitely confirmed. Total bacterial counts in the jejunal aspirate of the latter were lower than those usually associated with overgrowth $\left(>10^{5} / \mathrm{ml}\right)$, but the glucose-hydrogen breath test was equivocal in two. Although the symptoms of these patients have been relieved by treatment of subsequently diagnosed pathology, the possibility that they were due in part to overgrowth cannot be excluded. The isolation of similar organisms from controls, however, does suggest that colonisation of the norml small bowel may occur. 'Faecal' organisms isolated from the small bowel are considered likely to be implicated in the pathogenesis of symptoms, as their ability to deconjugate bile salts has been established. ${ }^{5}$ The majority of strains of G+NSR tested share this metabolic 

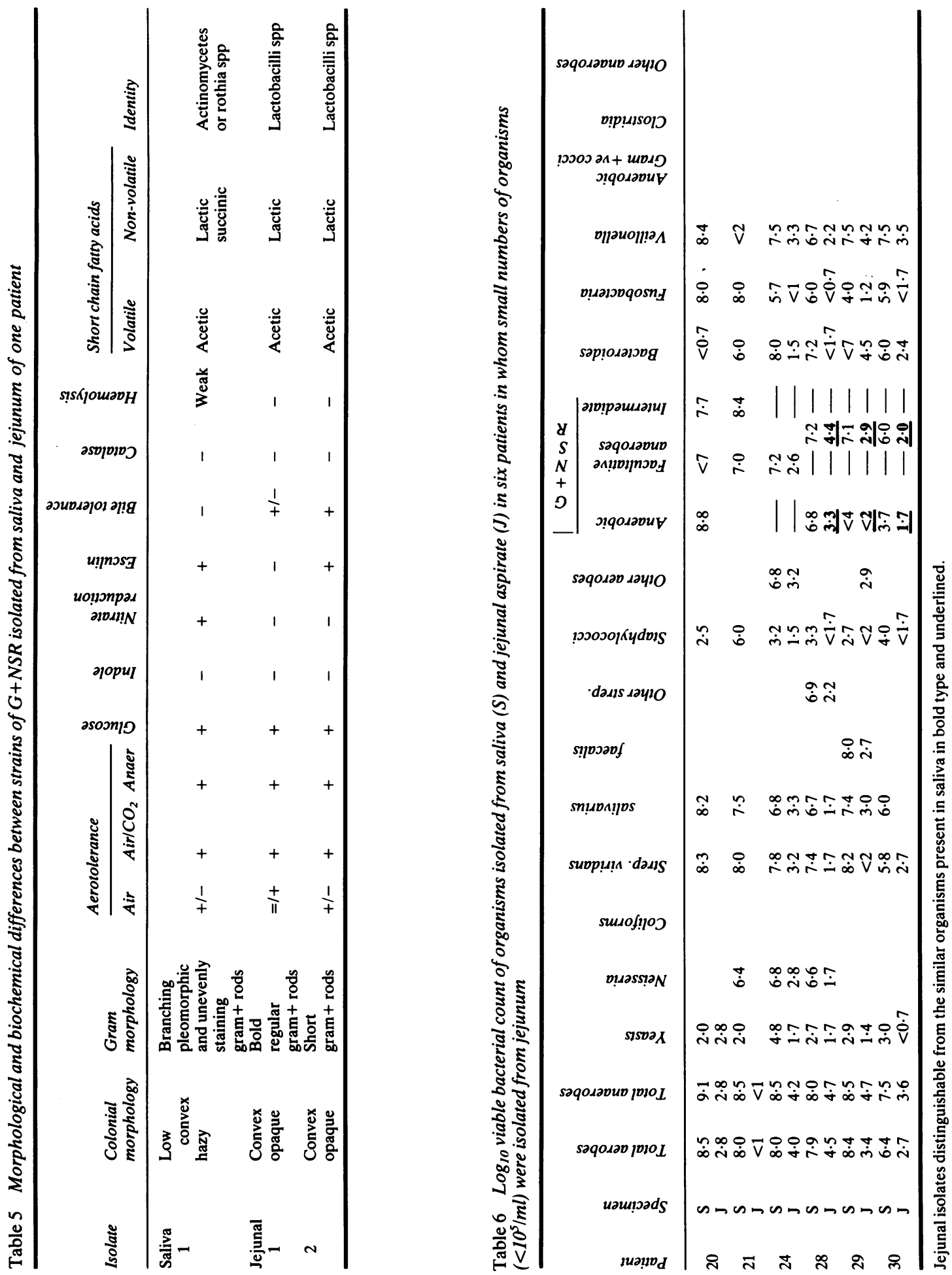
characteristic, ${ }^{6}$ and thus the 'salivary' organisms isolated from the jejunum of our subjects are also potentially capable of causing symptoms.

Detailed quantitative culture of saliva in addition to jejunal aspirate may allow organisms present in the jejunum to be distinguished from similar organisms present in saliva, and may therefore be useful in the investigation of patients in whom small bowel bacterial overgrowth is suspected.

\section{References}

1 Taylor RH, Avgerinos A, Taylor AJ, Hill MJ, Misiewicz JJ. Bacterial colonisation of the jejunum; an evaluation of five diagnostic tests. Gut 1981; 22: A442-3.

2 Drasar BS, Shiner M, McLeod GM. Studies on the intestinal flora. I. The bacterial flora of the gastrointestinal tract in healthy and achlorhydic persons. Gastroenterology 1969; 56: 71-9.

3 Drasar BS, Shiner M. Studies on the intestinal flora. II. Bacterial flora of the small intestine in patients with gastrointestinal disorders. Gut 1969; 10: 812-9.

4 Metz G, Gassull MA, Drasar BS, Jenkins DJA, Blendis LM. Breath hydrogen test for small intestinal bacterial colonisation. Lancet 1976; 1: 668-9.

5 Hill MJ, Drasar BS. Degradation of bile salts by human intestinal bacteria. Gut 1968; 9: 22-7.

6 Shimada K, Bricknell KS, Finegold SM. Deconjugation of bile acids by intestinal bacteria: review of literature and additional studies. $J$ Infect Dis 1969; 119: 273-81. 